\title{
Soybean SDS in South Africa is Caused by Fusarium brasiliense and a Novel Undescribed Fusarium sp.
}

Yared T. Tewoldemedhin and Sandra C. Lamprecht, ARC-Plant Protection Research Institute, Private Bag X5017, Stellenbosch, 7599, Western Cape, South Africa; and Martha M. Vaughan, Gail Doehring, and Kerry O'Donnell, Mycotoxin Prevention and Applied Microbiology Research Unit, Agricultural Research Service, United States Department of Agriculture, Peoria, IL 61604

\begin{abstract}
Soybean sudden death syndrome (SDS) was detected in South Africa for the first time during pathogen surveys conducted in 2013 to 2014. The primary objective of this study was to characterize the 16 slow-growing Fusarium strains that were isolated from the roots of symptomatic plants. Molecular phylogenetic analyses of a portion of translation elongation factor 1- $\alpha$ (TEF1) and the nuclear ribosomal intergenic spacer region (IGS rDNA) indicated that the etiological agents were Fusarium brasiliense and a novel, undescribed Fusarium sp. This is the first report of $F$. brasiliense outside of Brazil and Argentina and the novel Fusarium sp. causing

soybean SDS. Koch's postulates were completed for both fusaria on seven soybean cultivars that are commercially available in South Africa. Results of the pathogenicity experiment revealed that the strains of $F$. brasiliense and Fusarium sp. differed in aggressiveness to soybean, as reflected in differences in foliar symptoms, root rot, and reduction in shoot length. Cellfree culture filtrates of the two soybean SDS pathogens from South Africa and two positive control strains of $F$. virguliforme from the United States induced typical SDS symptoms on susceptible soybean cultivars in a whole-seedling assay, indicating that they contained phytotoxins.
\end{abstract}

Sudden death syndrome (SDS) of soybean (Glycine max (L.) Merr.) is widespread in North and South America, where it has caused significant losses in yield (Hartman et al. 1995; Rupe and Hartman 1999). For a period of 10 years (1996 to 2005), SDS was listed as one of the most important plant diseases in the United States (Wrather and Koenning 2006; Wrather et al. 2001). The causal organism was initially reported as Fusarium solani f. sp. glycines; however, molecular and morphological studies have identified four Fusarium spp. that cause soybean SDS (Aoki et al. 2003, 2005, 2012): Fusarium virguliforme O'Donnell \& T. Aoki; $F$. brasiliense T. Aoki \& O'Donnell; F. crassistipitatum Scandiani, T. Aoki \& O'Donnell; and F. tucumaniae T. Aoki, O'Donnell, Yosh. Homma \& Lattanzi). All four species are responsible for outbreaks of soybean SDS in South America; however, only F. virguliforme has been shown to cause SDS in North America (Mbofung et al. 2012; O'Donnell et al. 2010; Wang and Chilvers 2016).

The causal pathogens have been isolated most frequently from diseased roots and less frequently from lower stems but never from the leaves (Rupe 1989). Foliar symptoms, which include interveinal chlorosis and necrosis and, initially, chlorotic spots and leaf curling and wilting without root infection, appear to be caused by fungal toxins that are translocated to the leaves where chloroplasts are targeted (Brar and Bhattacharyya 2012; Hartman et al. 2004; Jin et al. 1996; $\mathrm{Li}$ et al. 1999). Root colonization and expression of foliar symptoms are affected by environmental (Scherm and Yang 1996), physical (Scherm et al. 1998), chemical (Rupe et al. 1993), and biological factors (McLean and Lawrence 1995; Melgar et al. 1994). Severity of SDS varies among years, which suggests that variation in environmental conditions such as soil moisture and temperature affect disease development (Wrather et al. 1995). Reports indicate that high levels of soil moisture and low soil temperatures, especially in early reproductive stages of the soybean, increase SDS severity (Hirrel 1987).

Corresponding author: Y. T. Tewoldemedhin;

E-mail: TewoldemedhinY@arc.agric.za

Mention of trade names or commercial products in this publication is solely for the purpose of providing specific information and does not imply recommendation or endorsement by the U.S. Department of Agriculture. USDA is an equal opportunity provider and employer.

Accepted for publication 3 August 2016.

C 2017 The American Phytopathological Society
Soil compaction that inhibits soil profile drainage and increases duration of soil saturation also can increase SDS due to its relationship with soil moisture (Rupe et al. 1993; Scherm et al. 1998). In addition, several studies have reported variation in aggressiveness of $F$. virguliforme isolates on soybean based on severity of foliar symptoms and root rot (Gray and Achenbach 1996; Li et al. 2009; Rupe et al. 2001).

Soybean is an important oilseed crop in South Africa, where approximately 1 million tons were produced on 687,300 ha during the 2014-15 growing season (Dredge 2015). When soybean SDS was first discovered in South Africa in 2013, it was reported as F. virguliforme based on BLASTn searches of the National Center for Biotechnology Information GenBank, using portions of translation elongation factor1- $\alpha$ gene (TEF1) and the nuclear ribosomal internal transcribed spacer region (ITS rDNA) as the queries (Tewoldemedhin et al. 2014). During the initial outbreak, leaf lesions typical of SDS were first observed in February 2013 on a farm in Lydenburg in the province of Mpumalanga planted to soybean ('PAN 737') for a second consecutive season. Symptoms developed at the R6 growth stage near physiological maturity of the soybean plants. Leaves exhibited interveinal chlorotic blotches that became necrotic while the veins remained green. These symptoms appeared throughout the plant but were most severe on the top leaves. Vascular tissue in the upper taproot and lower stem turned gray-brown and lateral roots exhibited decay but the pith remained white.

Additional soybean SDS isolates were recovered during 2014 field surveys in the provinces of Free State and North West (Table 1). Given this background, the primary objectives of the present study were to (i) identify the etiological agents employing molecular phylogenetics, (ii) complete Koch's postulates on soybean cultivars that are commercially available in South Africa, (iii) assess whether the SDS isolates differed in aggressiveness to soybean, and (iv) determine whether culture filtrates of the isolates could induce typical SDS symptoms on susceptible and moderately resistant cultivars in a feeding assay using intact seedlings (Brar and Bhattacharyya 2012; Swaminathan et al. 2016)

\section{Materials and Methods}

Pathogen isolation. In February 2014, soybean plants with typical SDS symptoms were sampled from national cultivar trial stations at Bethlehem in Free State province and Potchefstroom in North West province. In addition, eight SDS-causing Fusarium isolates previously reported as $F$. virguliforme (Tewoldemedhin et al. 2014) from the 2013 survey were included in this study to further evaluate their 
identity using molecular phylogenetics, and to evaluate their pathogenicity and aggressiveness on a range of soybean cultivars. Roots and crowns of symptomatic plants were washed and surface disinfested in $1 \%$ sodium hypochlorite $(\mathrm{NaOCl})$ for 1 min, rinsed twice in sterile distilled water, and allowed to dry in a laminar flow hood. Segments of diseased root and crown tissue were excised and plated on the following growth media: water agar with $0.02 \%$ novostreptomycin, potato dextrose agar (PDA) with $0.02 \%$ novostreptomycin, and selective Fusarium medium modified from Tio et al. (1977) by replacing Alisan with pentachloronitrobenzene at $0.05 \mathrm{~g} / \mathrm{liter}$. Twelve segments of plant material (six roots and six crowns) were plated per plant on each of the growth media. Slow-growing Fusarium spp. emerging from plant tissues were transferred to carnation leaf agar plates (Fisher et al. 1982) and single-spored before further work was conducted.

Pathogen characterization. Total genomic DNA was extracted from freeze-dried mycelium of 16 isolates from soybean fields with SDS symptoms in South Africa (Table 1) using a hexadecyltrimethylammonium bromide (Sigma-Aldrich) protocol, as previously described (O'Donnell et al. 1998a). A portion of TEF1 that spans three introns was polymerase chain reaction (PCR) amplified and sequenced as reported by O'Donnell et al. (1998b). The entire IGS rDNA region was PCR amplified with the primer pair NL11 and CNS1, then sequenced with four internal primers (Aoki et al. 2003). After DNA sequencing, reaction mixtures were run on an ABI-Hitachi 3730 automated capillary sequencer (Tokyo), and Sequencher (version 5.2.4; Gene Codes) was used to edit the sequence chromatograms. Maximum-likelihood (ML) phylogenetic reconstructions were conducted using GARLI ver. 2.10 (Zwickl 2006) on the CIPRES Science Gateway TeraGrid employing the GTR $+\mathrm{I}+\Gamma$ model of molecular evolution. Maximumparsimony (MP) analyses were implemented in PAUP*4.0b4a (Swofford 2003). Clade support was assessed by 2,400 ML and 1,000 MP bootstrap pseudoreplicates of the data. DNA sequences generated in the present study were deposited in GenBank as KX347978 to KX348005. The NEXUS and tree file were accessioned in TreeBASE as S19370 and Tr96425, respectively. Isolates identified as $F$. brasiliense and a novel, undescribed pathogen reported here as Fusarium sp. employing molecular phylogenetics were subjected to a PCR assay for MAT idiomorph (Hughes et al. 2014) to determine whether the MAT1-1 and MAT1-2 mating type idiomorphs of each species were present in South Africa.

Pathogenicity experiment. Sorghum grain inoculum was prepared by adapting the method described by Aoki et al. (2005). Grains were soaked in deionized water for $12 \mathrm{~h}(200 \mathrm{~g}$ of grain per $100 \mathrm{ml}$ of double-distilled $\mathrm{H}_{2} \mathrm{O}$ in 1-liter Schott bottles), then autoclaved for
$20 \mathrm{~min}$ at $120^{\circ} \mathrm{C}$ on two consecutive days after draining the excess water. The bottles were shaken before and after autoclaving. Autoclaved sorghum grains were inoculated with 10 mycelial discs (6 $\mathrm{mm}$ in diameter) excised from the growing edge of 16 of the SDS-causing Fusarium strains from South Africa (Table 1) cultured on PDA. As a negative control, bottles were inoculated with discs of noninoculated PDA. The bottles with inoculated sorghum grains were incubated at $25^{\circ} \mathrm{C}$ for 10 days and shaken every third day to ensure thorough grain colonization. Pathogenicity trials were conducted in a glasshouse $\left(18^{\circ} \mathrm{C}\right.$ night and $28^{\circ} \mathrm{C}$ day temperatures $)$ using plastic pots $(13 \mathrm{~cm}$ in diameter) with a holding capacity of $800 \mathrm{~g}$ of planting medium. The planting medium was made up of equal amounts of soil, perlite, and sand, which was pasteurized for $30 \mathrm{~min}$ at $83^{\circ} \mathrm{C}$ and left for 3 days before inoculum was introduced. A 12-g layer of infested sorghum grains was distributed in each pot (one-third empty), then covered with $2 \mathrm{~cm}$ of soil. Ten seeds of seven different soybean cultivars ('DM6.2iRR', 'LS6161R', 'LS6444R', 'NS5009R', 'NS5909R', 'PAN1454R', and 'PAN1664R') were added individually to each pot and covered with another $2 \mathrm{~cm}$ of the planting medium (Aoki et al. 2005). Pathogenicity and relative virulence of each isolate or tolerance or resistance of each cultivar were determined by evaluating shoot height, root rot, and leaf symptoms 5 weeks after planting. Plant height was measured from the soil line to shoot tip. Root rot severity was measured on a 0-to-4 scale, where $0=$ no symptoms and $1=1$ to $25,2=26$ to $50,3=51$ to 75 , and $4=76$ to $100 \%$ rot. Foliar symptom assessments were made using a visual disease rating based on a 1-to-5 disease severity scale (Hartman et al. 1997), where $1=$ no foliar symptoms, 2 = light symptom development with mottling and mosaic (1 to $20 \%$ foliage affected), 3 = moderate symptom development with interveinal chlorosis and necrosis (21 to 50\% foliage affected), 4 = heavy symptom development with interveinal chlorosis and necrosis (51 to $80 \%$ foliage affected), and $5=$ severe symptom development with interveinal chlorosis and necrosis or dead plants (81 to $100 \%$ foliage affected). To fulfill Koch's postulates, reisolations were made by plating 5-mm pieces of tissue excised from symptomatic crown and root tissues on PDA with $0.02 \%$ novostreptomycin, using the same surface-disinfesting protocol outlined above in the pathogen isolation section. The experimental design was a randomized complete block design with three block replicates for each treatment, and the trial was repeated once.

Preparation of cell-free culture filtrates for intact seedling assay. Two cultures of F. brasiliense (S1 and S8), four cultures of Fusarium sp. (S5, S6, S9, and S13) from South Africa, and two cultures of $F$. virguliforme from the United States (NRRL 22292 and 32478),

Table 1. Isolates recovered from soybean roots symptomatic for sudden death syndrome in three South African provinces

\begin{tabular}{|c|c|c|c|c|c|}
\hline Isolate & PPRIa & $\mathbf{K O D}^{\mathbf{b}}$ & Isolation date & Species $^{c}$ & Area, province \\
\hline $\mathrm{S} 1$ & PPRI13434 & 1163 & February 2013 & Fusarium brasiliense & Lydenburg, Mpumalanga \\
\hline $\mathrm{S} 2$ & PPRI13435 & 1164 & February 2013 & $F$. brasiliense & Lydenburg, Mpumalanga \\
\hline $\mathrm{S} 3$ & PPRI13436 & 1165 & February 2013 & F. brasiliense & Lydenburg, Mpumalanga \\
\hline S4 & PPRI13437 & 1166 & February 2013 & F. brasiliense & Lydenburg, Mpumalanga \\
\hline S5 & PPRI13438 & 1167 & February 2013 & Fusarium sp. & Lydenburg, Mpumalanga \\
\hline S6 & PPRI13439 & 1168 & February 2013 & Fusarium sp. & Lydenburg, Mpumalanga \\
\hline S7 & PPRI13440 & 1169 & February 2013 & F. brasiliense & Lydenburg, Mpumalanga \\
\hline S8 & PPRI13441 & 1170 & February 2013 & F. brasiliense & Lydenburg, Mpumalanga \\
\hline S9 & PPRI20927 & 1171 & February 2014 & Fusarium sp. & Bethlehem, Free State \\
\hline $\mathrm{S} 10$ & PPRI20926 & 1172 & February 2014 & Fusarium sp. & Bethlehem, Free State \\
\hline $\mathrm{S} 11$ & PPRI20925 & 1173 & February 2014 & Fusarium sp. & Bethlehem, Free State \\
\hline $\mathrm{S} 12$ & PPRI20924 & 1174 & February 2014 & Fusarium sp. & Bethlehem, Free State \\
\hline $\mathrm{S} 13$ & PPRI20923 & 1175 & February 2014 & Fusarium sp. & Bethlehem, Free State \\
\hline S14 & PPRI20922 & 1176 & February 2014 & F. brasiliense & Bethlehem, Free State \\
\hline $\mathrm{S} 15$ & PPRI20921 & 1177 & February 2014 & F. brasiliense & Potchefstroom, North West \\
\hline S16 & PPRI20920 & 1178 & February 2014 & F. brasiliense & Bethlehem, Free State \\
\hline
\end{tabular}

${ }^{a}$ Plant Protection Research Institute (Agricultural Research Council) culture collection number.

${ }^{\mathrm{b}} \mathrm{KOD}=$ accession number in O'Donnell lab, United States Department of Agriculture-Agricultural Research Service, Peoria, IL.

${ }^{\mathrm{c}}$ F. brasiliense and Fusarium sp. were both strongly supported as genealogically exclusive species-level lineages in the translation elongation factor $1-\alpha+$ nuclear ribosomal intergenic spacer region phylogeny. 
which were selected as the positive control because they have been shown to induce soybean SDS ( $\mathrm{Li}$ et al. 2009), were cultured on Bilay's agar (Booth 1971) in plastic petri dishes (100 by $15 \mathrm{~mm}$; Corning, Thomas Scientific) for 2 weeks in the dark. The entire contents of each culture was transferred aseptically to a 300-ml flask containing $100 \mathrm{ml}$ of modified Septoria medium containing $4.3 \mathrm{~g}$ of Sigma-Aldrich MS-salt mix (M5524) supplemented with $3 \mathrm{~g}$ of $\mathrm{KNO}_{3}, 2 \mathrm{~g}$ of yeast extract, and sucrose at $30 \mathrm{~g} /$ liter, which was adjusted to $\mathrm{pH} 4.5$ before autoclaving. After 2 weeks of incubation at $25^{\circ} \mathrm{C}$ in the dark without shaking, the cultures were filtered through 22 - to $25-\mu \mathrm{m}$ pore size Miracloth (Calbiochem), then passed through a 150-ml, 0.2- $\mu \mathrm{m}$ filtration unit (Nalgene, Thermo Fisher). The filtrate $\mathrm{pH}$ was adjusted to 6.0 prior to testing for phytotoxicity on intact seedlings. Culture filtrates were diluted in Hoagland's number 2 basal salt solution (H2395; Sigma-Aldrich) to 4 and $10 \%$ and used immediately in the first and second experiments, respectively.

Preparation of soybean for intact seedling assay. In the first experiment, moderately resistant 'MN1606' and susceptible 'Spencer' soybean were assayed; then, a second, independent experiment was conducted using only susceptible 'Sloan'. The soybean cultivars selected for cell-free culture filtrate assays varied from those utilized in pathogenicity experiments due to differences in cultivar availability in the United States, where the intact-seedling SDS assays were performed. Seed were germinated in deionized water for $24 \mathrm{~h}$

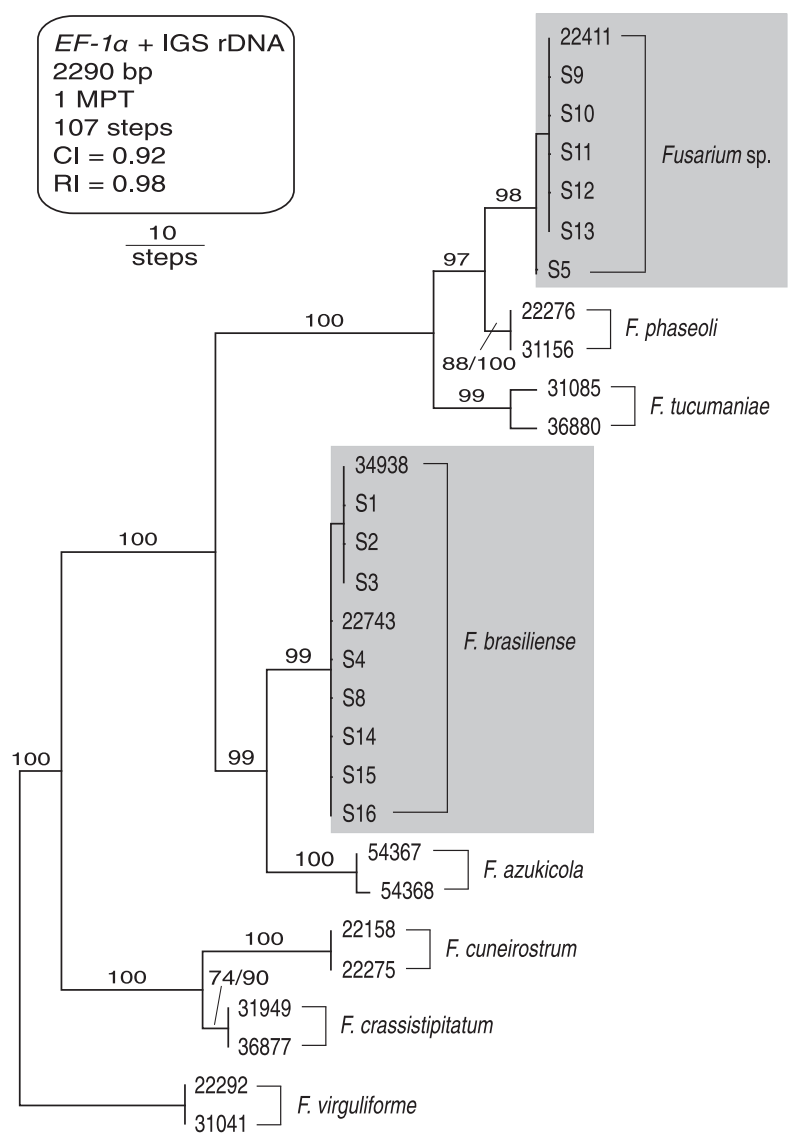

Fig. 1. Single most-parsimonious tree (MPT) inferred from a 687-bp portion of elongation factor 1- $\alpha(E F-1 \alpha)$ and 1,603-bp portion of the nuclear ribosomal intergenic spacer region (IGS rDNA) (2,290-bp alignment) for 29 isolates representing eight sudden death syndrome and bean root rot (SDS-BRR) clade species. Gray highlight and the $\mathrm{S}$ prefix are used to identify eight strains of Fusarium brasiliense and six strains of a novel Fusarium sp. responsible for soybean SDS in South Africa. The phylogram was rooted on sequences of $F$. virguliforme based on the results of more inclusive analyses (O'Donnell et al. 2010). Numbers at the nodes represent maximum-parsimony (MP) bootstrap (BS) support $\geq 70 \%$ based on 1,000 pseudoreplicates of the data. The maximumlikelihood (ML) BS value is only shown when it differed by more than $\geq 5 \%$ of the MP BS score (MP-BS/ML-BS). $\mathrm{Cl}=$ consistency index and $\mathrm{RI}=$ retention index. (approximately 100 seed per $80 \mathrm{ml}$ of deionized water in a 150-by$15-\mathrm{mm}$ petri plate), then planted in plastic pots $(6.5$ by 6.5 by $9 \mathrm{~cm}$ high) with Seramis (ACE Gardening Products Inc.) clay pellets to enable removal of the intact seedlings with its root mass (Vaughan et al. 2011). Plants were then cultivated at $25^{\circ} \mathrm{C}$ in a greenhouse for 3 weeks. Each 3-week-old seedling was then removed from the Seramis and transferred to a 50-ml disposable polypropylene centrifuge tube (Fisher Scientific) containing $40 \mathrm{ml}$ of Hoagland's number 2 basal salt mixture amended with 4 or $10 \%$ of a cell-free culture filtrate of $F$. brasiliense or Fusarium sp. from South Africa or F. virguliforme from the United States (Swaminathan et al. 2016). The negative control consisted of Hoagland's solution without a culture filtrate. Within $24 \mathrm{~h}$, the plants had taken up the initial $40 \mathrm{ml}$ of solution containing any potential toxin in the culture filtrate. Plants were then supplied with adequate Hoagland's solution and grown hydroponically in the greenhouse during the 2-week assay. SDS symptoms were visually scored on a scale of 1 to 5 , where $1=$ $<10 \%$ chlorosis, $2=10$ to $20 \%$ chlorosis, $3=20$ to $50 \%$ chlorosis, $4=50$ to $80 \%$ chlorosis and necrosis, and $5=$ entire leaf chlorotic or necrotic. Additionally, the chlorophyll content in each leaflet of the second trifoliate leaf was measured following a published protocol (Brar and Bhattacharyya 2012). Each leaf was photographed and the area was determined using Image $\mathbf{J}$ software (Schneider et al. 2012).

Statistical analysis. Levene's variance ratio test was performed to test for homogeneity of trial variance between the trial repeats (Levene 1960). Data of the two independent trials were considered block treatments, providing that Levene's variance ratio test showed homogeneity in trial variance. Data were also subjected to analysis of variance (ANOVA) using SAS statistical software (version 9.2; SAS Institute Inc.), and the Shapiro-Wilk test was performed to test for normality (Shapiro and Wilk 1965). In cases where deviations from normality were due to kurtosis and not skewness, the data were accepted as reliable and the results were interpreted without transformation (Glass et al. 1972). The Student's $t$ least significant difference (LSD) was calculated at the 5\% confidence level to compare treatment means for significant effects. To assess differences among SDS symptoms and leaf chlorophyll contents in the three soybean cultivars following treatments with the culture filtrate, a nineby-three (isolate by cultivar) ANOVA was performed. Individual pairwise comparisons were determined using Student's $t$-LSD at the $5 \%$ confidence level.

\section{Results}

Pathogen isolation and identification. In addition to the eight soybean SDS isolates recovered during the 2013 field survey of Mpumalanga province in South Africa (Tewoldemedhin et al. 2014), eight slow-growing Fusarium isolates were recovered during 2014 surveys in Bethlehem and Potchefstroom in the provinces of Free State and North West, respectively (Table 1). To determine the phylogenetic identity of these isolates, DNA sequence data were obtained from the intron-rich $5^{\prime}$ portion of the TEF1 gene (687-bp alignment) and the variable midregion of the IGS rDNA (1,603-bp alignment). These sequences were aligned with those of seven named species within the SDS-bean root rot (BRR) clade, together with one putatively novel species represented by NRRL 22411 Fusarium sp. (Hughes et al. 2014). Each partition was analyzed individually and as a combined data set (Fig. 1) via MP using PAUP* (Swofford 2003). MP analysis of the combined dataset (2,290 bp) identified two most-parsimonious trees 107 steps in length (consistency index = 0.92 , retention index $=0.98$ ), in which 94 of the 97 variable nucleotide positions were parsimony informative. MP and ML bootstrap (BS) analyses of the two-locus dataset robustly placed nine of the South African SDS isolates within $F$. brasiliense (MP-BS/ML-BS = $99 \%$ ) and seven within a genealogically exclusive lineage with NRRL 22411 Fusarium sp. (MP-BS/ML-BS = 98\%; PPRI13439 Fusarium sp. and PPRI13440 F. brasiliense were not included in Figure 1). A sister-group relationship between Fusarium sp. and F. phaseoli was strongly supported by bootstrapping (Fig. 1; MP$\mathrm{BS}=97 \%$ and ML-BS $=95 \%$ ). The PCR assay for mating type 
revealed that the isolates of $F$. brasiliense and Fusarium sp. from South Africa all possessed a MAT1-1 idiomorph.

Pathogenicity experiment. The error variance ratios of the shoot height, root rot and foliar symptom data for the pathogenicity trials was $P<0.0001$. Therefore, a weighted analysis was conducted initially in order to combine the data sets from the two trials; then, the combined data were used for remaining statistical analyses (John and Quenouille 1977). ANOVA on shoot height, root rot, and foliar symptom severity showed that there were significant $(P<0.0001)$ species-cultivar and isolate-cultivar interactions (Table 2). Although $F$. brasiliense did not reduce shoot height of PAN1454R, it and Fusarium sp. significantly reduced shoot height in all of the other cultivars compared with the noninoculated control. In addition, no significant difference in shoot height was observed between $F$. brasiliense and Fusarium sp. in all cultivars tested, except that shoot height recorded after DM6.2iRR was inoculated with Fusarium sp. was significantly lower compared with that recorded for $F$. brasiliense (Table 3 ). Both species caused significantly higher root rot severity compared with the uninfested controls. However, in PAN1454R and DM6.2iRR, inoculation with Fusarium sp. resulted in significantly higher root rot severity ratings compared with when they were inoculated with $F$. brasiliense. F. brasiliense and Fusarium sp. induced significantly higher foliar symptom severity in all cultivars tested compared with the noninoculated control. Except for the greater severity of foliar symptoms for DM6.2iRR inoculated with Fusarium sp. compared with $F$. brasiliense (Table 3), no other significant differences were observed in foliar symptoms between the two species on the cultivars tested.

Cultivars reacted differently to the isolates tested. LS6161R was affected the most in that all of the isolates reduced shoot height significantly except for $F$. brasiliense isolate S2. The two cultivars affected the least were LS6444R, on which four isolates of $F$. brasiliense (S1, S2, S7, and S8) and two isolates of Fusarium sp. (S5 and S6) did not reduce shoot height significantly; and PAN1454R, on which six isolates of $F$. brasiliense (S1, S3, S4, S7, S8, and S15) and four isolates of Fusarium sp. (S5, S6, S9, and S12) did not reduce shoot height significantly. Interestingly, two isolates, F. brasiliense $\mathrm{S} 2$ and Fusarium sp. S5, did not reduce shoot height in most of the cultivars evaluated, while $F$. brasiliense S16 did not reduce shoot height significantly in NS5909R and DM6.2iRR. By way of contrast, $F$. brasiliense isolates S1 and S4 reduced shoot height significantly in all the cultivars except PAN1454R. In addition, Fusarium sp. isolates $\mathrm{S} 9, \mathrm{~S} 10, \mathrm{~S} 11, \mathrm{~S} 12$, and $\mathrm{S} 13$ and $F$. brasiliense isolates $\mathrm{S} 14$ and S15 reduced shoot height significantly in all seven cultivars (Table 4). All of the isolates caused significant root rot on all of the cultivars. However, root rot severity recorded for isolates $F$. brasiliense S2 and Fusarium sp. S5 was significantly lower than for the other isolates tested, whereas $F$. brasiliense isolates $\mathrm{S} 14$ and $\mathrm{S} 15$ and Fusarium sp. isolates S10, S11, S12, and S13 caused significantly higher root rot compared with the other isolates (Table 5).

The seven cultivars evaluated for severity of foliar symptoms reacted differently to the different isolates. $F$. brasiliense isolates S1, S3, S4, S7, S8, and S15 and Fusarium sp. isolates S9, S10, $\mathrm{S} 11, \mathrm{~S} 12$, and $\mathrm{S} 13$ caused significantly more severe foliar symptoms on all cultivars compared with the uninfested controls. Similar results were obtained for Fusarium sp. S6 and F. brasiliense S14, except on LS6161R, and for $F$. brasiliense isolate S16, except on NS5909R. Severity of foliar symptoms induced by F. brasiliense S2 and Fusarium $\mathrm{sp}$. S5 isolates did not differ significantly from that of the noninoculated controls (Table 6).

Table 2. Analysis of variance for effect of two sudden death syndrome pathogens (Fusarium brasiliense and Fusarium sp.) on mean shoot height, root rot, and foliar symptoms on 5-week-old seedlings of seven soybean cultivars ${ }^{\mathrm{a}}$

\begin{tabular}{|c|c|c|c|c|c|c|c|}
\hline \multirow[b]{2}{*}{ Source } & \multirow[b]{2}{*}{ DF } & \multicolumn{2}{|c|}{ Shoot height } & \multicolumn{2}{|c|}{ Root rot } & \multicolumn{2}{|c|}{ Foliar symptom } \\
\hline & & MS & $P$ value & MS & $P$ value & MS & $P$ value \\
\hline Rep (Trial) & 5 & $16,651.19$ & 0.0402 & 0.58 & 0.3549 & 4.39 & 0.4026 \\
\hline Isolates & 16 & $355,657.51$ & $<0.0001$ & 179.20 & $<0.0001$ & 282.17 & $<0.0001$ \\
\hline Species & 2 & $714,687.83$ & $<0.0001$ & 861.42 & $<0.0001$ & 723.35 & $<0.0001$ \\
\hline F. brasiliense & 8 & $184,092.96$ & $<0.0001$ & 66.87 & $<0.0001$ & 159.98 & $<0.0001$ \\
\hline Fusarium sp. & 6 & $463,808.73$ & $<0.0001$ & 101.53 & $<0.0001$ & 298.98 & $<0.0001$ \\
\hline Cultivar & 6 & $213,439.71$ & $<0.0001$ & 3.69 & $<0.0001$ & 39.75 & $<0.0001$ \\
\hline Species x Cultivar & 12 & $17,938.27$ & $<0.0001$ & 3.84 & $<0.0001$ & 13.60 & 0.0013 \\
\hline Isolate $\mathrm{x}$ Cultivar & 96 & $18,496.59$ & $<0.0001$ & 2.29 & $<0.0001$ & 11.76 & $<0.0001$ \\
\hline Error & 2,757 & $1,526.07$ & $\ldots$ & 0.17 & $\ldots$ & 0.001 & $\ldots$ \\
\hline Corrected Total & 2,880 & $\ldots$ & $\ldots$ & $\ldots$ & $\ldots$ & $\ldots$ & $\ldots$ \\
\hline
\end{tabular}

${ }^{\mathrm{a}} \mathrm{DF}=$ degree of freedom, $\mathrm{MS}=$ mean square, and $P$ value $<0.05=$ statistically significant.

Table 3. Effect of Fusarium brasiliense (F. bras) Fusarium sp., and an noninoculated negative control on shoot height, root rot, and foliar symptoms on seven soybean cultivars under glasshouse conditions

\begin{tabular}{|c|c|c|c|c|c|c|c|c|c|}
\hline \multirow[b]{2}{*}{ Cultivar } & \multicolumn{3}{|c|}{ Shoot height $(\mathbf{m m})^{\mathbf{a}}$} & \multicolumn{3}{|c|}{$\operatorname{Root}^{\operatorname{rot}^{b}}$} & \multicolumn{3}{|c|}{ Foliar symptoms ${ }^{\mathrm{c}}$} \\
\hline & Control & F. bras & Fusarium sp. & Control & F. bras & Fusarium sp. & Control & F. bras & Fusarium sp. \\
\hline DM6.2iRR & 301.2 & 214.2 & 183.4 & 0.00 & 2.93 & 3.37 & 1.00 & 2.58 & 3.79 \\
\hline LS6161R & 295.7 & 179.8 & 176.9 & 0.00 & 3.25 & 3.37 & 1.00 & 3.72 & 3.25 \\
\hline LS6444R & 225.3 & 168.0 & 150.4 & 0.00 & 3.39 & 3.37 & 1.00 & 3.98 & 4.00 \\
\hline NS5009R & 231.2 & 148.9 & 134.4 & 0.00 & 3.19 & 3.38 & 1.00 & 3.49 & 4.03 \\
\hline NS5909R & 305.1 & 216.2 & 192.6 & 0.00 & 3.24 & 3.40 & 1.00 & 3.72 & 3.95 \\
\hline PAN1454R & 219.7 & 201.1 & 194.9 & 0.00 & 3.34 & 3.66 & 1.00 & 3.90 & 4.11 \\
\hline PAN1664R & 274.0 & 183.0 & 173.2 & 0.00 & 3.24 & 3.42 & 1.00 & 4.02 & 4.04 \\
\hline $\operatorname{LSD}_{(P<0.05)^{\mathrm{d}}}$ & 24.68 & $\ldots$ & $\ldots$ & $\ldots$ & 0.257 & $\ldots$ & $\ldots$ & 0.758 & $\ldots$ \\
\hline
\end{tabular}

a Plant height was measured from the soil line to shoot tip in millimeters.

${ }^{\mathrm{b}}$ Root rot severity was measured on a 0 -to- 4 scale, where $0=$ no symptoms and $1=1$ to $25,2=26$ to $50,3=51$ to 75 and $4=76$ to $100 \%$ rot.

${ }^{c}$ Assessments were made using a visual disease rating based on a 1-to-5 disease severity scale (Hartman et al. 1997), where $1=$ no foliar symptoms, $2=$ light symptom development with mottling and mosaic ( 1 to $20 \%$ foliage affected), $3=$ moderate symptom development with interveinal chlorosis and necrosis ( 21 to $50 \%$ foliage affected), $4=$ heavy symptom development with interveinal chlorosis and necrosis ( 51 to $80 \%$ foliage affected), and $5=$ severe symptom development with interveinal chlorosis and necrosis or dead plants (81 to $100 \%$ foliage affected).

${ }^{\mathrm{d}}$ Least significant difference. 
Intact seedling assay with cell-free culture filtrates. According to the ANOVA model, cultivar type was a significant contributing factor to differences among SDS symptoms $(P<0.0001)$. As expected, moderately resistant MN1606 displayed the least amount of symptoms, and only plants treated with filtrate from $F$. virguliforme 22292 were significantly different from the noninoculated control (Table 7). All of the culture filtrates tested appeared to elicit an SDS response in both of the susceptible cultivars. However, the response was not significant for one isolate from each of the species tested (S8, 32478, and S5) on Spencer and Fusarium sp. isolate S6 on Sloan. Nevertheless, Fusarium sp. isolates S6, S9, and S13 induced a comparable degree of SDS symptoms as the positive control isolate $F$. virguliforme 22292 in Spencer. Isolate S13 also elicited comparable symptoms to $F$. virguliforme 22292 in Sloan.

Measurements of leaf chlorophyll content similarly indicated that all of the isolate filtrates induced chlorosis in soybean; however, the degree of reduced chlorophyll varied by cultivar (Table 8). Consistent with the visual symptom scoring, which indicated that most isolate filtrates did have an effect on moderately resistant MN1606, the leaf chlorophyll content was significantly reduced by all of the isolates tested. Fusarium sp. S13 had the greatest effect on MN1606 chlorophyll content; this effect was similar to that produced by the filtrate of $F$. virguliforme 22292. Interestingly, isolate S6 that had the greatest effect on Spencer had the least effect on Sloan, where the chlorophyll content was not significantly different from the control untreated plants. Fusarium sp. S13 had the greatest effect on Sloan leaf chlorophyll content. Despite the variability among the isolates, it is apparent that just the cell-free culture filtrates of the three soybean pathogens were able to elicit an SDS response in different soybean cultivars.

\section{Discussion}

The molecular phylogenetic analyses indicate that $F$. brasiliense and a novel, undescribed soybean SDS pathogen reported here as Fusarium sp. were recovered in two and three of the South African provinces surveyed, respectively. Although $F$. brasiliense isolate S15 was the only SDS pathogen recovered in Potchefstroom in North West province, F. brasiliense (S14 and S16) and Fusarium sp. (S9,

Table 4. Score of shoot height (in millimeters) on seven soybean cultivars in response to inoculation with different South African isolates of Fusarium brasiliense and Fusarium sp. ${ }^{\text {a }}$

\begin{tabular}{|c|c|c|c|c|c|c|c|}
\hline Species, isolate & DM6.2iRR & LS6161R & LS6444R & NS5009R & NS5909R & PAN1454R & PAN1664R \\
\hline Control & 301.2 & 295.7 & 225.3 & 231.2 & 305.1 & 219.7 & 274.0 \\
\hline \multicolumn{8}{|l|}{ F. brasiliense } \\
\hline $\mathrm{S} 1$ & 159.7 & 154.9 & 160.5 & 140.8 & 171.9 & 211.9 & 181.6 \\
\hline S2 & 287.3 & 253.3 & 252.3 & 231.2 & 342.2 & 160.4 & 289.9 \\
\hline S3 & 188.8 & 195.9 & 208.2 & 148.7 & 203.8 & 225.9 & 192.5 \\
\hline $\mathrm{S} 4$ & 205.8 & 183.5 & 160.7 & 135.5 & 200.1 & 224.9 & 184.4 \\
\hline S7 & 238.3 & 212.3 & 186.7 & 142.5 & 210.3 & 245.9 & 194.4 \\
\hline S8 & 191.2 & 190.8 & 195.7 & 133.5 & 227.5 & 223.5 & 190.0 \\
\hline S14 & 164.2 & 170.0 & 107.7 & 126.0 & 162.7 & 154.1 & 101.9 \\
\hline S15 & 193.9 & 172.3 & 134.4 & 114.0 & 140.9 & 185.9 & 153.1 \\
\hline S16 & 285.1 & 137.7 & 128.0 & 180.9 & 291.7 & 172.0 & 151.8 \\
\hline \multicolumn{8}{|l|}{ Fusarium sp. } \\
\hline S5 & 237.4 & 243.2 & 236.8 & 225.4 & 328.6 & 279.7 & 258.8 \\
\hline S6 & 244.8 & 238.3 & 194.0 & 169.9 & 260.3 & 231.8 & 216.7 \\
\hline S9 & 182.9 & 189.6 & 157.7 & 121.5 & 185.0 & 183.2 & 159.3 \\
\hline $\mathrm{S} 10$ & 154.3 & 143.9 & 120.3 & 113.6 & 144.3 & 175.7 & 145.8 \\
\hline S11 & 146.6 & 134.6 & 105.4 & 109.8 & 137.0 & 151.8 & 131.3 \\
\hline $\mathrm{S} 12$ & 139.9 & 115.5 & 124.4 & 109.8 & 122.9 & 185.2 & 152.5 \\
\hline $\mathrm{S} 13$ & 132.9 & 122.3 & 98.6 & 81.2 & 142.3 & 133.7 & 124.6 \\
\hline
\end{tabular}

a Aboveground plant height (in millimeters) was measured from the soil line to tallest leaf tip. Least significant difference $(P<0.05)=42.52$.

Table 5. Score of root rot on seven soybean cultivars in response to inoculation with different South African isolates of Fusarium brasiliense and Fusarium sp. ${ }^{\text {a }}$

\begin{tabular}{|c|c|c|c|c|c|c|c|}
\hline Species, isolate & DM6.2iRR & LS6161R & LS6444R & NS5009R & NS5909R & PAN1454R & PAN1664R \\
\hline Control & 0.00 & 0.00 & 0.00 & 0.00 & 0.00 & 0.00 & 0.00 \\
\hline \multicolumn{8}{|l|}{ F. brasiliense } \\
\hline $\mathrm{S} 1$ & 3.46 & 3.58 & 3.20 & 3.41 & 3.63 & 3.37 & 3.74 \\
\hline $\mathrm{S} 2$ & 1.70 & 1.58 & 1.78 & 2.05 & 1.81 & 2.27 & 1.52 \\
\hline $\mathrm{S} 3$ & 2.75 & 3.17 & 3.55 & 3.00 & 3.52 & 3.61 & 3.44 \\
\hline $\mathrm{S} 4$ & 2.93 & 2.95 & 3.04 & 3.54 & 3.70 & 2.93 & 3.19 \\
\hline S7 & 2.78 & 2.83 & 3.28 & 3.19 & 3.24 & 3.04 & 2.86 \\
\hline S8 & 2.36 & 2.57 & 3.00 & 2.78 & 2.93 & 2.97 & 2.60 \\
\hline S14 & 3.86 & 3.62 & 4.00 & 3.96 & 4.00 & 4.00 & 4.00 \\
\hline S15 & 3.92 & 4.00 & 4.00 & 4.00 & 4.00 & 4.00 & 3.96 \\
\hline S16 & 2.30 & 3.97 & 3.93 & 2.67 & 2.23 & 4.00 & 3.96 \\
\hline \multicolumn{8}{|l|}{ Fusarium sp. } \\
\hline S5 & 1.71 & 1.68 & 1.73 & 2.09 & 1.83 & 2.56 & 1.63 \\
\hline S6 & 2.80 & 3.18 & 3.04 & 2.86 & 3.00 & 3.54 & 3.04 \\
\hline S9 & 3.64 & 3.21 & 3.18 & 3.12 & 3.43 & 3.67 & 3.80 \\
\hline $\mathrm{S} 10$ & 4.00 & 4.00 & 3.96 & 3.96 & 4.00 & 4.00 & 3.94 \\
\hline $\mathrm{S} 11$ & 4.00 & 4.00 & 4.00 & 3.83 & 3.89 & 4.00 & 3.96 \\
\hline $\mathrm{S} 12$ & 4.00 & 4.00 & 3.96 & 3.96 & 4.00 & 4.00 & 4.00 \\
\hline S13 & 3.87 & 4.00 & 3.77 & 4.00 & 3.96 & 4.00 & 4.00 \\
\hline
\end{tabular}

a Values represent severity of root rot scored on a 0 -to- 4 scale, where $0=$ no symptom and $1=1$ to $25,2=26$ to $50,3=51$ to 75 , and $4=76$ to $100 \%$ rot. Least significant difference $(P<0.05)=0.442$. 
$\mathrm{S} 10, \mathrm{~S} 11, \mathrm{~S} 12$, and S13) were isolated from symptomatic plants collected at Bethlehem in Free State. Multilocus genotyping also revealed that six of the eight isolates previously reported as $F$. virguliforme from the Lydenburg area in Mpumalanga province were $F$. brasiliense (PPRI13434, PPRI13435, PPRI13436, PPRI13437, PPRI13440, and PPRI13441) and two were the putatively novel soybean SDS pathogen Fusarium sp. (PPRI13438 and PPRI13439) (Tewoldemedhin et al. 2014). Prior to the present study, F. brasiliense was only known from soybean symptomatic for SDS in Brazil and Argentina (Aoki et al. 2005; O'Donnell et al. 2010), whereas the Fusarium sp. was represented by only a single isolate recovered from Phaseolus vulgaris in California and deposited in the ARS culture collection as $F$. solani f. sp. phaseoli) (NRRL $22411=\mathrm{BBA}$ $64394=$ CBS $265.50=$ ATCC 38466). Without the benefit of multiple isolates of Fusarium sp., which allowed us to determine that it and $F$. phaseoli are reciprocally monophyletic sisters, NRRL 22411 was erroneously reported as $F$. phaseoli in a singlenucleotide polymorphism-based multilocus genotyping assay for SDS-BRR pathogen determination (O'Donnell et al. 2010).

The present study has extended our knowledge of the host range and geographic distribution of the Fusarium sp. represented by NRRL 22411 via the discovery that it causes soybean SDS in South Africa. It remains to be determined whether this pathogen can cause BRR, as previously thought, given the host from which NRRL 22411 was originally isolated (O'Donnell et al. 2010). However, with the completion of Koch's postulates, it represents the fifth species within the SDS-BRR clade of Fusarium that can cause soybean SDS. Given our working hypothesis that the SDS-BRR fusaria likely evolved in South America (Aoki et al. 2003; O'Donnell 2000), we speculate that $F$. brasiliense and Fusarium sp. were introduced into South Africa recently on infested soybean, presumably from South America. Currently, it is unknown what New World hosts the soybean SDS pathogens evolved on; however, it clearly wasn't soybean because this Asian host has only been cultivated in South America for the past century (Simpson and Conner-Ogorzaly 2001).

Results of the PCR assay for MAT idiomorph show that, in contrast to Brazil, where MAT1-1 and MAT1-2 strains of F. brasiliense are present (Hughes et al. 2014), only MAT1-1 strains were detected in South Africa. Similarly, only the MAT1-1 idiomorph of Fusarium sp. was detected in the eight isolates of this SDS pathogen in South Africa. The latter finding is noteworthy because the only other strain of this species, NRRL 22411 Fusarium sp. from P. vulgaris in California, possesses a MAT1-2 idiomorph (Hughes et al. 2014). Taken together, these results suggest that both species might possess a heterothallic sexual reproductive mode. Additional pathogen surveys

Table 7. Score of sudden death syndrome (SDS) foliar symptoms on three North American soybean cultivars following treatment with cell-free culture filtrates in an intact seedling assay ${ }^{a}$

\begin{tabular}{llccc}
\hline Species & Isolate & MN1606 & Spencer & Sloan \\
\hline Control & Control & 1.00 & 1.00 & 1.00 \\
F. brasiliense & S1 & 1.00 & 3.00 & 3.00 \\
& S8 & 1.00 & 2.00 & 3.40 \\
F. virguliforme & 22292 & 2.33 & 3.75 & 3.00 \\
& 32478 & 1.00 & 1.75 & 2.40 \\
Fusarium sp. & S5 & 1.33 & 2.00 & 2.20 \\
& S6 & 1.00 & 2.75 & 1.40 \\
& S9 & 1.00 & 3.25 & 2.00 \\
& S13 & 1.00 & 3.00 & 2.80 \\
LSD $_{(P<0.05)}{ }^{\mathrm{b}}$ & .. & 0.93 & 1.65 & 0.98 \\
\hline
\end{tabular}

a Values represent SDS foliar symptoms scored as follows: $1=<10 \%$ chlorosis, $2=10$ to $20 \%$ chlorosis, $3=20$ to $50 \%$ chlorosis, $4=50$ to $80 \%$ chlorosis and necrosis, and $5=$ entire leaf chlorotic or necrotic.

${ }^{\mathrm{b}}$ Least significant difference.

Table 8. Average leaflet chlorophyll content (in milligrams) of three North American soybean cultivars following treatment with cell-free culture filtrates in an intact seedling assay

\begin{tabular}{llccc}
\hline Species & Isolate & MN1606 & Spencer & Sloan \\
\hline Control & Control & 188 & 198 & 79 \\
F. brasiliense & S1 & 106 & 65 & 47 \\
& S 8 & 91 & 114 & 57 \\
F. virguliforme & 22292 & 91 & 73 & 52 \\
& 32478 & 130 & 89 & 61 \\
Fusarium sp. & S5 & 112 & 87 & 55 \\
& S6 & 99 & 56 & 78 \\
& S9 & 139 & 124 & 50 \\
& S13 & 56 & 64 & 40 \\
$\operatorname{LSD}_{(P<0.05)}{ }^{\text {a }}$ & .. & 46 & 37 & 16 \\
\hline
\end{tabular}

${ }^{\mathrm{a}}$ Least significant difference.

Table 6. Score of foliar symptoms on seven soybean cultivars in response to inoculation with different South African isolates of Fusarium brasiliense and Fusarium sp. ${ }^{\mathrm{a}}$

\begin{tabular}{|c|c|c|c|c|c|c|c|}
\hline Species, isolate & DM6.2iRR & LS6161R & LS6444R & NS5009R & NS5909R & PAN1454R & PAN1664R \\
\hline Control & 1.00 & 1.00 & 1.00 & 1.00 & 1.00 & 1.00 & 1.00 \\
\hline \multicolumn{8}{|l|}{ F. brasiliense } \\
\hline S1 & 2.58 & 4.35 & 3.67 & 3.05 & 3.48 & 2.67 & 3.78 \\
\hline S2 & 1.00 & 1.00 & 1.00 & 1.00 & 1.00 & 1.42 & 1.00 \\
\hline S3 & 3.00 & 2.92 & 4.00 & 2.39 & 3.92 & 4.00 & 4.00 \\
\hline S4 & 2.36 & 2.58 & 4.39 & 4.65 & 5.00 & 4.00 & 4.43 \\
\hline S7 & 2.63 & 3.65 & 4.35 & 4.67 & 4.66 & 3.33 & 4.00 \\
\hline S8 & 3.79 & 4.22 & 4.29 & 3.63 & 4.71 & 5.00 & 4.68 \\
\hline S14 & 4.00 & 1.63 & 5.00 & 5.00 & 4.30 & 5.00 & 4.73 \\
\hline S15 & 2.44 & 4.37 & 3.26 & 3.96 & 5.00 & 5.00 & 4.65 \\
\hline S16 & 1.33 & 5.00 & 4.71 & 2.67 & 1.00 & 4.69 & 5.00 \\
\hline \multicolumn{8}{|l|}{ Fusarium sp. } \\
\hline S5 & 1.00 & 1.00 & 1.35 & 1.36 & 1.35 & 1.00 & 1.33 \\
\hline S6 & 3.00 & 2.00 & 3.00 & 3.24 & 3.35 & 4.07 & 4.00 \\
\hline S9 & 5.00 & 3.04 & 4.32 & 5.00 & 4.36 & 5.00 & 4.68 \\
\hline S10 & 5.00 & 4.17 & 5.00 & 4.64 & 5.00 & 4.64 & 4.71 \\
\hline S11 & 5.00 & 4.05 & 5.00 & 4.56 & 5.00 & 5.00 & 5.00 \\
\hline $\mathrm{S} 12$ & 4.26 & 5.00 & 5.00 & 4.77 & 4.43 & 4.73 & 5.00 \\
\hline S13 & 3.40 & 5.00 & 4.29 & 4.47 & 4.50 & 4.56 & 4.05 \\
\hline
\end{tabular}

a Values represent severity of foliar symptoms scored using a 1-to-5 disease severity scale (Hartman et al. 1997), where $1=$ no foliar symptoms, $2=$ light symptom development with mottling and mosaic ( 1 to $20 \%$ foliage affected), 3 = moderate symptom development with interveinal chlorosis and necrosis ( 21 to $50 \%$ foliage affected), $4=$ heavy symptom development with interveinal chlorosis and necrosis (51 to $80 \%$ foliage affected), and $5=$ severe symptom development with interveinal chlorosis and necrosis or dead plants (81 to $100 \%$ foliage affected). Least significant difference $(P<0.05)=1.306$. 
are needed to determine whether both idiomorphs of $F$. brasiliense and Fusarium sp. are present in South Africa, because pathogens that reproduce sexually are more likely to overcome host resistance than those that only reproduce clonally (Covert et al. 2007; McDonald and Linde 2002).

The South African isolates of F. brasiliense and Fusarium sp. generally caused high levels of foliar symptoms and root rot, and reduced shoot height. The level of aggressiveness of the two species was generally equal in almost all the cultivars evaluated. However, in a few instances, Fusarium sp. was more aggressive than F. brasiliense based on the evaluated measurements. Variability in aggressiveness was observed for isolates from both species. For instance, even though $F$. brasiliense isolate $\mathrm{S} 2$ caused root rot on all cultivars, it failed to induce foliar symptoms on the cultivars evaluated, except on PAN1454R, and it was only on this cultivar that it reduced shoot height. In addition, Fusarium sp. isolate S5 caused root rot on all cultivars but did not induce foliar symptoms on three cultivars. Interestingly, this isolate reduced shoot growth without exhibiting any foliar symptoms on LS6161R and DM6.2iRR. Foliar symptoms in SDS were proposed to be caused by radicicol and proteinaceous fungal toxins produced on or in colonized roots and translocated to the leaves (Hartman et al. 2004; Jin et al. 1996). Li et al. (1999) showed that SDS-like foliar symptoms developed when cell-free culture filtrates containing one or more toxins were fed to cut soybean seedlings. Recently, Pudake et al. (2013) and Chang et al. (2016) reported that the FvTox 1 and FvNIS1 phytotoxins, respectively, are major virulence factors involved in foliar SDS development in soybean. Consequently, it is possible that certain fungal isolates are effective in colonizing the host root but may not be good toxin producers and, conversely, some isolates may be relatively poor root colonizers but may or may not be good toxin producers. In our study, the poor root colonizing isolates generally caused less severe foliar symptoms and did not reduce shoot growth significantly. However, there were a few instances where the poor root colonizers that induced less severe or no foliar symptoms also reduced shoot growth. This phenomenon was also reported by Li et al. (2009).

Most of the cultivars evaluated in the present study showed more or less consistent reaction to the isolates. In general, cultivars with high root rot severity also exhibited extensive foliar symptoms and stunted shoot growth. However, there were few cases where cultivars reacted differently to a specific isolate or isolates. F. brasiliense isolate $\mathrm{S} 14$ caused high root rot severity, extensive foliar symptoms, and stunted shoot growth on all cultivars. However, the severity rating for foliar symptoms induced by this isolate on LS6161R was the lowest in comparison with the other cultivars evaluated. This may be due to the root rot severity on this cultivar that was relatively the lowest and shoot growth the highest compared with other cultivars infested with the same isolate. It is worth mentioning here that some of the other $F$. brasiliense isolates (S3, S4, S7, S8, S15, and S16) caused extensive foliar symptoms on this cultivar. In addition, F. brasiliense isolate S16 induced high root rot severity, stunted shoot growth, and extensive foliar symptoms on four cultivars (LS6161R, LS6444R, PAN1454R, and PAN1664R). However, on NS5909R and DM6.2iRR, it induced little root rot and little to no foliar symptoms, and had an insignificant effect on shoot growth. By way of contrast, even though $F$. brasiliense isolate S16 induced little root rot on NS5009R, it caused significant reduction in shoot growth and incited moderate foliar symptoms. This suggests that the above-mentioned cultivars may have some mechanism to either reduce infection by the specific isolates or interfere in the virulent mechanisms (i.e., toxins) that are responsible for the foliar symptoms.

According to data obtained from the intact seedling assay with cell-free culture filtrates, the $F$. brasiliense and Fusarium sp. isolates tested were capable of causing SDS-like foliar symptoms in the absence of root colonization or rot, which is consistent with the production of fungal toxins. Additionally, the amount of toxin produced by each isolate likely varies because the foliar symptoms between isolate filtrates varied. As expected, moderately resistant MN1606 displayed the least amount of symptoms. However, the species and isolate that caused the greatest amount of symptoms and chlorosis was different on susceptible Spencer and Sloan, which is consistent with the variability observed between the seven cultivars in the pathogenicity experiments. The persistence of cultivar differences in response to cell-free culture filtrates favors the hypothesis of an alternative mechanism in soybean for coping with the fungal toxins that are responsible for the foliar SDS symptoms.

In previous research conducted with $F$. virguliforme, soybean cultivar resistance response has been evaluated primarily based on severity of leaf symptoms (Stephens et al. 1993) rather than decreased colonization of roots by the pathogen. For instance, Gray and Achenbach (1996) reported that SDS-inducing isolates caused crown and root rot of soybean and differences in foliar symptoms but there was no difference in root rot severity between the moderately resistant 'Ripley' and the susceptible Spencer. Similarly, Rupe (1989) and Hartman et al. (1997) also showed that there was no difference in root infection between cultivars rated for their susceptibility or resistance based on foliar symptom rating. However, Luckew et al. (2013) used four disease parameters (foliar disease incidence, foliar leaf scorch disease severity, area under disease progress curve, and root rot severity) to investigate disease resistance of soybean lines by evaluating 14 quantitative trait loci (QTL). Based on their finding that some of the QTL were associated with more than one of the disease parameters, it is theoretically possible that several QTL can be stacked to develop soybean cultivars with greater resistance to SDS.

\section{Acknowledgments}

We thank the Protein Research Foundation, Agricultural Research Council, and the United States Department of Agriculture-Agricultural Research Service for supporting this research; S. Swaminathan (Iowa State University) for a detailed protocol for conducting the cell-free whole seedling assay; S. Swaminathan and M. Chilvers (Michigan State University) for soybean seed of the susceptible and moderately resistant cultivars; F. Calitz for statistical analysis of the data; and N. Orwig, J. Teresi, A. Wallenfang, A. Schoeman, and T. Phasoana for technical assistance.

\section{Literature Cited}

Aoki, T., O’Donnell, K., Homma, Y., and Lattanzi, A. R. 2003. Sudden death syndrome of soybean is caused by two morphologically and phylogenetically distinct species within the Fusarium solani species complex-F. virguliforme in North America and F. tucumaniae in South America. Mycologia 95: 660-684.

Aoki, T., O'Donnell, K., and Scandiani, M. M. 2005. Sudden death syndrome of soybean in South America is caused by four species of Fusarium: Fusarium brasiliense sp. nov., F. cuneirostrum sp. nov., F. tucumaniae, and F. virguliforme. Mycoscience 46:162-183.

Aoki, T., Scandiani, M. M., and O’Donnell, K. 2012. Phenotypic, molecular phylogenetic and pathogenic characterization of Fusarium crassistipitatum sp. nov., a novel soybean sudden death syndrome pathogen from Argentina and Brazil. Mycoscience 53:167-186.

Booth, C. 1971. The Genus Fusarium. Commonwealth Mycological Institute, Kew, Surrey, UK.

Brar, H. K., and Bhattacharyya, M. K. 2012. Expression of a single-chain variablefragment antibody against a Fusarium virguliforme toxin peptide enhances tolerance to sudden death syndrome in transgenic soybean plants. Mol. PlantMicrobe Interact. 25:817-824.

Chang, H.-X., Domier, L. L., Radwan, O., Yendrek, C. R., Hudson, M. E., and Hartman, G. L. 2016. Identification of multiple phytotoxins produced by Fusarium virguliforme including a phytotoxic effector (FVNIS1) associated with sudden death syndrome foliar symptoms. Mol. Plant-Microbe Interact. 29:96-108.

Covert, S. F., Aoki, T., O’Donnell, K., Starkey, D., Holliday, A., Geiser, D. M., Cheung, F., Town, C., Strom, A., Juba, J., Scandiani, M., and Yang, X. B. 2007. Sexual reproduction in the soybean sudden death syndrome pathogen Fusarium tucumaniae. Fungal Genet. Biol. 44:799-807.

Dredge, R. D. 2015. Crop estimates committee of Department of Agriculture, Forestry and Fisheries, South Africa. www.daff.gov.za/daffweb3/Home/CropEstimates and www.sagis.org.za/cec.html

Fisher, N. L., Burgess, L. W., Toussoun, T. A., and Nelson, P. E. 1982. Carnation leaves as a substrate and for preserving cultures of Fusarium species. Phytopathology 72:151-153.

Glass, G. V., Peckham, P. D., and Sanders, J. R. 1972. Consequences of failure to meet assumptions underlying the fixed effects analyses of variance and covariance. Rev. Educ. Res. 42:237-288.

Gray, L. E., and Achenbach, L. A. 1996. Severity of foliar symptoms and root and crown rot of soybean inoculated with various isolates and inoculum rates of Fusarium solani. Plant Dis. 80:1197-1199. 
Hartman, G. L., Huang, Y. H., and Li, S. 2004. Phytotoxicity of Fusarium solani culture filtrates from soybean and other hosts assayed by stem cuttings. Australas. Plant Pathol. 33:9-15.

Hartman, G. L., Huang, Y. H., Nelson, R. L., and Noel, G. R. 1997. Germplasm evaluation of Glycine max for resistance to Fusarium solani, the causal organism of sudden death syndrome. Plant Dis. 81:515-518.

Hartman, G. L., Noel, G. R., and Gray, L. E. 1995. Occurrence of soybean sudden death syndrome in east-central Illinois and associated yield losses. Plant Dis. 79: 314-318.

Hirrel, M. C. 1987. Sudden death syndrome of soybean: New insights into its development. Pages 95-104 in: Am. Seed Trade Assoc. 16th Soybean Res. Conf.

Hughes, T. J., O’Donnell, K., Sink, S., Rooney, A. P., Scandiani, M. M., Luque, A., Bhattacharyya, M. K., and Huang, X. 2014. Genetic architecture and evolution of the mating type locus in fusaria that cause soybean sudden death syndrome and bean root rot. Mycologia 106:686-697.

Jin, H., Hartman, G. L., Nickell, C. D., and Widholm, J. M. 1996. Characterization and purification of a phytotoxin produced by Fusarium solani, the causal agent of soybean sudden death syndrome. Phytopathology 86:277-282.

John, J. A., and Quenouille, M. H. 1977. Experiments: Design and Analysis. Charles Griffin \& Co. Ltd., London.

Levene, H. 1960. Robust test in the equality of variance. Pages 278-292 in: Contributions to Probability and Statistics. I. Olkin, ed. Stanford University Press, Palo Alto, CA.

Li, S., Hartman, G. L., and Chen, Y. 2009. Evaluation of aggressiveness of Fusarium virguliforme isolates that cause soybean sudden death syndrome. Plant Pathol. 91:77-86.

Li, S., Hartman, G. L., and Widholm, J. M. 1999. Viability staining of soybean suspension-cultured cells and a seedling stem cutting assay to evaluate phytotoxicity of Fusarium solani f. sp. glycines culture filtrates. Plant Cell Rep. 18:375-380.

Luckew, A. S., Leandro, L. F., Bhattacharyya, M. K., Nordman, D. J., Lightfoot, D. A., and Cianzio, S. R. 2013. Usefulness of 10 genomic regions in soybean associated with sudden death syndrome resistance. Theor. Appl. Genet. 126: 2391-2403.

Mbofung, G. Y. C., Harrington, T. C., Steimel, J. T., Navi, S. S., Yang, X. B., and Leandro, L. F. 2012. Genetic structure and variation in aggressiveness in Fusarium virguliforme in the Midwest United States. Can. J. Plant Pathol. 34:83-97.

McDonald, B. A., and Linde, C. 2002. Pathogen population genetics, evolutionary potential, and durable resistance. Annu. Rev. Phytopathol. 40:349-379.

McLean, K. S., and Lawrence, G. W. 1995. Development of Heterodera glycines as affected by Fusarium solani, the causal agent of sudden death syndrome of soybean. J. Nematol. 27:70-77.

Melgar, J., Roy, K. W., and Abney, T. S. 1994. Sudden death syndrome of soybean: Etiology, symptomology, and effects of irrigation and Heterodera glycines on incidence and severity under field conditions. Can. J. Bot. 72: 1647-1653.

O'Donnell, K. 2000. Molecular phylogeny of the Nectria haematococca-Fusarium solani species complex. Mycologia 92:919-938.

O'Donnell, K., Cigelnik, E., and Nirenberg, H. 1998a. Molecular systematics and phylogeography of the Gibberella fujikuroi species complex. Mycologia 90: 465-493.

O’Donnell, K., Kistler, H. C., Cigelnik, E., and Ploetz, R. C. 1998b. Multiple evolutionary origins of the fungus causing Panama disease of banana: Concordant evidence from nuclear and mitochondrial gene genealogies. Proc. Natl. Acad. Sci. USA 95:2044-2049.

O’Donnell, K., Sink, S., Scandiani, M. M., Luque, A., Colletto, A., Biasoli, M., Lenzi, L., Salas, G., González, V., Ploper, L. D., Formento, N., Pioli, R. N., Aoki, T., Yang, X. B., and Sarver, B. A. J. 2010. Soybean sudden death syndrome species diversity within North and South America revealed by multilocus genotyping. Phytopathology 100:58-71.

Pudake, R. N., Swaminathan, S., Sahu, B. B., Leandro, L. F., and Bhattacharyya, M. K. 2013. Investigation of the Fusarium virguliforme fvtoxl mutants revealed that the FvTox 1 toxin is involved in foliar sudden death syndrome development in soybean. Curr. Genet. 59:107-117.

Rupe, J. C. 1989. Frequency and pathogenicity of Fusarium solani recovered from soybeans with sudden death syndrome. Plant Dis. 73:581-584.

Rupe, J. C., Correll, J. C., Guerber, J. C., Becton, C. M., Gbur, E. E., Cummings, M. S., and Yount, P. A. 2001. Differentiation of the sudden death syndrome pathogen of soybean, Fusarium solani f. sp. glycines, from other isolates of $F$. solani based on cultural morphology, pathogenicity, and mitochondrial DNA restriction fragment length polymorphisms. Can. J. Bot. 79:829-835.

Rupe, J. C., and Hartman, G. L. 1999. Sudden death syndrome. Pages 37-39 in: Compendium of Soybean Diseases. G. L. Hartman, J. B. Sinclair, and J. C. Rupe, eds. American Phytopathological Society, St. Paul, MN.

Rupe, J. C., Sabbe, W. E., Robbins, R. T., and Gbur, E. E., Jr. 1993. Soil and plant factors associated with sudden death syndrome of soybean. J. Prod. Agric. 6:218-221.

Scherm, H., and Yang, X. B. 1996. Development of sudden death syndrome of soybean in relation to soil temperature and soil water potential. Phytopathology 86:642-649.

Scherm, H., Yang, X. B., and Lundeen, P. 1998. Soil variables associated with sudden death syndrome in soybean fields in Iowa. Plant Dis. 82:1152-1157.

Schneider, C. A., Rasband, W. S., and Eliceiri, K. W. 2012. NIH Image to ImageJ: 25 years of image analysis. Nat. Methods 9:671-675.

Shapiro, S. S., and Wilk, M. B. 1965. An analysis of variance test for normality (complete samples). Biometrika 52:591-611.

Simpson, B. B., and Conner-Ogorzaly, M. 2001. Economic Botany: Plants in Our World. McGraw-Hill, New York

Stephens, P. A., Nickell, C. D., and Lim, S. M. 1993. Sudden death syndrome development in soybean cultivars differing in resistance to Fusarium solani. Crop Sci. 33:63-66.

Swaminathan, S., Abeysekara, N. S., Liu, M., Cianzio, S. R., and Bhattacharyya, M. K. 2016. Quantitative trait loci underlying host responses of soybean to Fusarium virguliforme toxins that cause foliar sudden death syndrome. Theor. Appl. Genet. 129:495-506.

Swofford, D. L. 2003. PAUP* 4.0b10: Phylogenetic Analysis Using Parsimony (*and other methods). Sinauer Associates, Sunderland, MA.

Tewoldemedhin, Y. T., Lamprecht, S. C., Geldenhuys, J. J., and Kloppers, F. J. 2014. First report of soybean sudden death syndrome caused by Fusarium virguliforme in South Africa. Plant Dis. 98:569.

Tio, M., Burgess, L. W., Nelson, P. E., and Toussoun, T. A. 1977. Techniques for the isolation, culture and preservation of the fusaria. Aust. Plant Pathol. Soc. Newsl. 6:11-13.

Vaughan, M. M., Tholl, D., and Tokuhisa, J. G. 2011. An aeroponic culture system for the study of root herbivory on Arabidopsis thaliana. Plant Methods 7:5.

Wang, J., and Chilvers, M. I. 2016. Development and characterization of microsatellite markers for Fusarium virguliforme and their utility within clade 2 of the Fusarium solani species complex. Fungal Ecol. 20:7-14.

Wrather, J. A., Anderson, T. R., Arsyad, D. M., Tan, Y., Ploper, L. D., Porta-Puglia, A., Ram, H. H., and Yorinori, J. T. 2001. Soybean disease loss estimates for the top 10 soybean producing countries in 1998. Can. J. Plant Pathol. 23:115-121.

Wrather, J. A., Kendig, S. R., Amand, S. C., Niblack, T. C., and Smith, G. S. 1995 Effect of tillage, cultivar, and planting date on percentage of soybean leaves with symptoms of sudden death syndrome. Plant Dis. 79:560-562.

Wrather, J. A., and Koenning, S. R. 2006. Estimates of disease on soybean yields in the United States 2003 to 2005. J. Nematol. 38:173-180.

Zwickl, D. J. 2006. Genetic algorithm approaches for the phylogenetic analysis of large biological sequence datasets under the maximum likelihood criterion. $\mathrm{Ph} . \mathrm{D}$. dissertation, The University of Texas Press, Austin. 